\title{
Sperm-associated antigen 5 is a potential biomarker for poor prognosis in breast cancer
}

\author{
XIAOLI ZHOU ${ }^{1 *}$, LIZHOU JIA ${ }^{2}$, YANGYANG SUN ${ }^{1}$, LINGYUN XU $^{1}$, XUDONG WANG ${ }^{3}$ and QI TANG ${ }^{2 *}$ \\ ${ }^{1}$ Department of Pathology, The Affiliated Changzhou No. 2 People's Hospital of Nanjing Medical University, \\ Changzhou, Jiangsu 213003; ${ }^{2}$ Department of Pathology, Nanjing Medical University, Nanjing, Jiangsu 211166; \\ ${ }^{3}$ Department of Clinical Bio-bank, Nantong University Affiliated Hospital, Nantong, Jiangsu 226001, P.R. China
}

Received March 18, 2018; Accepted October 15, 2018

DOI: $10.3892 /$ ol.2018.9729

\begin{abstract}
Sperm-associated antigen 5 (SPAG5) is currently considered to serve a role in promoting tumor cell growth and is overexpressed in several types of human cancer. However, to the best of our knowledge, the association of SPAG5 with molecular subtypes of patients with breast cancer (BC) remains to be fully investigated. Reverse transcription-quantitative polymerase chain reaction and immunohistochemistry on tissue microarrays were used in the current study to detect the expression levels of SPAG5 mRNA and protein, respectively, in BC. The association between SPAG5 mRNA and protein levels, and clinical characteristics and prognostic information were investigated. SPAG5 mRNA and protein levels were identified to be higher in BC tissues compared with matched adjacent nontumor tissues. High expression level of SPAG5 protein was associated with tumor size, histological grade, estrogen receptor expression, Ki-67 expression, lymph node status, tumor-node-metastasis (TNM) stage and the triple-negative BC subtype. In addition, high expression level of SPAG5 protein was associated with a poor prognosis in patients with BC. In summary, the current study suggests that SPAG5 is a novel and useful prognostic biomarker in BC.
\end{abstract}

\section{Introduction}

Breast cancer (BC) is one of the most common cancer types in women. Approximately 1.68 million women are diagnosed

Correspondence to: Professor Xiaoli Zhou, Department of Pathology, The Affiliated Changzhou No. 2 People's Hospital of Nanjing Medical University, 188 Gehu Road, Changzhou, Jiangsu 213003, P.R. China

E-mail: zxlpear@sina.com

Dr Qi Tang, Department of Pathology, Nanjing Medical University, 101 Longmian Road, Nanjing, Jiangsu 211166, P.R. China

E-mail: qitang@njmu.edu.cn

*Contributed equally

Key words: sperm-associated antigen 5, breast cancer, biomarker with $\mathrm{BC}$ worldwide each year and it ranks as the leading cause of cancer-associated cases of mortality in women (1). Although China is a country with a lower incidence of $\mathrm{BC}$, incidence and mortality still ranks the highest for $\mathrm{BC}$ in female malignant cancer types (2-4). BC is a heterogeneous disease that exhibits high sensitivity to chemotherapeutic treatment; approximately $50 \%$ of patients with advanced breast cancer benefit from combined chemotherapy, whereas the other half experience only the adverse effects from chemotherapy drugs (5). Therefore, it is important to further refine $\mathrm{BC}$ molecular classification to more precisely guide treatment decisions. There are four $\mathrm{BC}$ molecular subtypes, including luminal A, luminal B, human epidermal growth factor receptor 2 (HER2) overexpression and triple-negative (TN) (6). Significant differences have been identified in the prognosis and treatment efficacy among patients with different molecular subtypes of BC (7). Although the existing molecular subtyping provides an improved basis for the treatment and prognosis of patients, certain patients with heterogeneous BC remain insensitive to clinical treatment (8).

Sperm-associated antigen 5 (SPAG5), first identified in 2001, is also known as mitotic spindle-associated protein 5 (9-11). SPAG5 is involved in the formation of spindles during the cell cycle and may be closely associated with the function and movement of spindles during mitosis $(12,13)$. Certain studies have also reported that SPAG5 may inhibit cell apoptosis through the inhibition of mammalian target of rapamycin complex 1 (14). In 2016, Abdel-Fatah et al (15) revealed that SPAG5 is an amplified gene in BC and may have clinical utility as a biomarker in estrogen receptor (ER)-negative $\mathrm{BC}$, however this study did not examine the association between SPAG5 and the molecular classification of BC.

The current study analyzed SPAG5 expression in Chinese patients with primary BC and compared it with the expression level in matched adjacent nontumor tissues. The association between SPAG5 expression, clinical characteristics, $\mathrm{ER} /$ progesterone receptor (PR)/HER2/Ki-67 expression and overall survival (OS) in patients with $\mathrm{BC}$ was also investigated.

\section{Materials and methods}

Human tissue specimens and patient clinical information. A total of 379 formalin-fixed, paraffin-embedded (FFPE) breast tissue samples were collected from 159 female patients with 
an age range of 24-87 years. This included 159 cancer tissue samples, 159 matched adjacent nontumor tissue samples and 61 benign tumor tissue samples. All tissue blocks were obtained from the Department of Pathology at the Affiliated Hospital of Nantong University (Jiangsu, China) between July 2003 and March 2010. Medical records for tissue donor patients included information on age, histological grade,ER expression, PR expression, HER2 expression, Ki-67 expression, tumor size, lymph node metastasis and tumor-node-metastasis (TNM) stage. No patients received treatment, including radiation therapy, chemotherapy or immunotherapy, prior to surgical resection. OS was defined as the period from initial diagnosis of $\mathrm{BC}$ via biopsy until mortality. Information on patients who were alive at the last follow-up date was removed from the analysis. Disease-free survival was defined as the period from surgical treatment until disease recurrence. In addition, a total of 35 freshly frozen BC tumor tissues and matching adjacent nontumor tissues were obtained from a subset of the 159 patients at the Affiliated Hospital of Nantong University. Written informed consent was obtained from all patients involved in the current study. The Human Research Ethics Committee of the Affiliated Hospital of Nantong University approved the study protocol.

Tissue microarrays (TMAs) and immunohistochemistry (IHC). TMAs were generated at the Department of Pathology, Affiliated Hospital of Nantong University, using a Quick Ray manual tissue microarrayer system (cat. no. UT06; Unitma Co., Ltd., Seoul, Korea). Specifically, core tissue biopsies ( $2 \mathrm{~mm}$ in diameter) were obtained from 159 individuals. FFPE blocks were made and then arranged in new recipient paraffin blocks (cat. no. 62595-08; Quick-Ray ${ }^{\mathrm{TM}}$ Recipient Block; Head Biotechnology Co., Ltd., Beijing, China), according to the manufacturer's protocol. A total of five breast TMAs were made. Sections $(4 \mu \mathrm{m})$ were cut and placed on super frost-charged glass microscope slides to generate TMA slides. Tissue sections were deparaffinized and rehydrated through a graded series of alcohols. Endogenous peroxidase activity was blocked by incubation in $3 \% \mathrm{H}_{2} \mathrm{O}_{2}$. Tissues were placed in $0.01 \mathrm{M}$ citrate buffer at $\mathrm{pH} 6.0$ and heated to boiling in a microwave for antigen retrieval. SPAG5 was detected using a polyclonal rabbit anti-human SPAG5 antibody for $2 \mathrm{~h}$ at room temperature (1:1,000; cat. no. HPA022008; Atlas Antibodies, Bromma, Sweeden). Reactions were detected using an Envision ${ }^{\mathrm{TM}}$ peroxidase kit (Dako; Agilent Technologies, Inc., Santa Clara, CA, USA). Tissues were then incubated in $0.05 \%$ 3,3'-diaminobenzidine (Dako, Agilent Technologies, Inc.) for $30 \mathrm{sec}$ at room temperature, counterstained with $0.45 \%$ hematoxylin for $3 \mathrm{~min}$, dehydrated through a graded series of alcohols, cleared in xylene and coverslipped with permanent mounting media at room temperature.

Staining was quantified in all tissues without knowledge of clinical characteristics. SPAG5 expression was scored using the semi-quantitative $\mathrm{H}$-score method, which takes into account both the staining intensity and the percentage of cells at that intensity $(10,11)$. The following staining intensity scores were used: 0 indicated no staining; $1+$ indicated weak staining; $2+$ indicated moderate staining; and $3+$ indicated intense staining The total number of cells at each intensity level was multiplied by the corresponding intensity score to yield an intensity percentage score. Final staining scores were calculated by summing the four intensity percentage scores. The minimum possible final staining score was 0 (no staining) and the maximum possible score was 300 (100\% of cells with $3+$ staining intensity).

Reverse transcription-quantitative polymerase chain reaction (RT-qPCR). RT-qPCR was performed to determine the SPAG5 mRNA expression level in 35 pairs of human $\mathrm{BC}$ tissue and matched adjacent nontumor tissue. Tissue samples were snap-frozen in liquid nitrogen and stored at $-80^{\circ} \mathrm{C}$ prior to RNA extraction. Total RNA was extracted from frozen samples using TRIzol reagent (Invitrogen; Thermo Fisher Scientific, Inc., Waltham, MA, USA) and reverse transcribed into cDNA using a PrimeScript ${ }^{\mathrm{TM}}$ RT reagent kit (Clontech Laboratories, Inc., Mountainview, CA, USA), according to the manufacturer's protocol. Human $\beta$-actin served as the internal control for determining SPAG5 mRNA levels. The following primers were used for qPCR: human $\beta$-actin forward, 5'-TGGAGAAAATCTGGC ACCAC-3' and reverse, 5'-GATGATGCCTCGTTCTAC-3'; and SPAG5 forward, 5'-CATCTCACAGTGGGATAACTA ATAAAC-3' and reverse, 5'-CAGGGATAGGTGAAGCAA GGATA-3' (GenScript, Nanjing, Jiangsu China). qPCR was performed using an ABI PRISM 7500HT Sequence Detection system (Applied Biosystems; Thermo Fisher Scientific, Inc.) in 96-well plates. The final volume for each reaction was $20 \mu \mathrm{l}$, which included $2 \mu \mathrm{l}$ of cDNA template (corresponding to $\sim 40 \mathrm{ng}$ of retro-transcribed total RNA), the primers (20 nmol/1 each) and 2X SYBR-Green PCR Master mixture (10 $\mu 1)$. Thermocycling conditions were as follows: Following an initial $2 \mathrm{~min}$ at $50^{\circ} \mathrm{C}$ to allow AmpErase-UNG activity and $10 \mathrm{~min}$ at $95^{\circ} \mathrm{C}$, samples were cycled 40 times at $95^{\circ} \mathrm{C}$ for $15 \mathrm{sec}$ and $58^{\circ} \mathrm{C}$ for $1 \mathrm{~min}$. All experiments were performed in triplicate. mRNA levels were quantified using the $2^{-\Delta \Delta \mathrm{Cq}}$ method (16) and normalized to respective internal controls.

Statistical analysis. All statistical analyses were performed using the SPSS 18.0 statistical software package (SPSS Inc., Chicago, IL, USA). For statistical analysis, the continuous SPAG5 expression data from IHC were first converted into dichotic data (low vs. high) using specific cutoff values, which were selected based on significant differences in OS using the X-tile software program (www.tissuearray. org/rimmlab) (14). Statistical analysis of the RT-qPCR data was performed using an unpaired Student's t-test when two groups were compared. $\chi^{2}$ test was used to identify statistical differences between groups. Cumulative patient survival was estimated using the Kaplan-Meier method and a log-rank test was used to compare the survival curves. A Cox proportional hazards model was used to calculate univariate and multivariate hazard ratios (HRs) for the variables. $\mathrm{P}<0.05$ was considered to indicate a statistically significant difference.

\section{Results}

SPAG5 mRNA is highly expressed in BC tissues. The expression levels of SPAG5 mRNA in BC tissues and matched adjacent nontumor tissues were examined using RT-qPCR. The SPAG5 mRNA expression level was 3.41 \pm 0.41 -fold higher in $\mathrm{BC}$ tissues compared with matched adjacent nontumor tissues $(\mathrm{P}<0.001$; Fig. 1A). In addition, it was identified that the SPAG5 mRNA expression level was $1.81 \pm 0.31$-fold higher in TNBC tissues compared with other $\mathrm{BC}$ molecular subtypes $(\mathrm{P}<0.001$; Fig. 1B). 
Table I. SPAG5 protein expression in breast tissues.

SPAG5 expression, $\mathrm{n}(\%)$

\begin{tabular}{lrcccr} 
Tissue type & $\mathrm{n}$ & Low or no & High & $\chi^{2}$ & P-value \\
\hline Breast cancer tissues & 159 & $43(27.04)$ & $116(72.96)$ & & \\
Matched adjacent tissues & 159 & $159(100.00)$ & $0(0.00)$ & 60.700 & $<0.001$ \\
Benign tumor tissues & 61 & $59(96.72)$ & $2(3.28)$ & & \\
\hline
\end{tabular}

SPAG5, sperm-associated antigen 5 .

$\mathbf{A}$

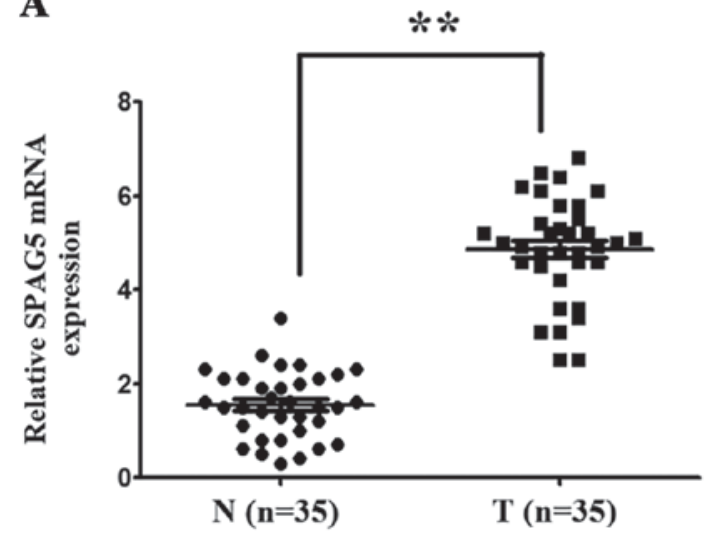

B

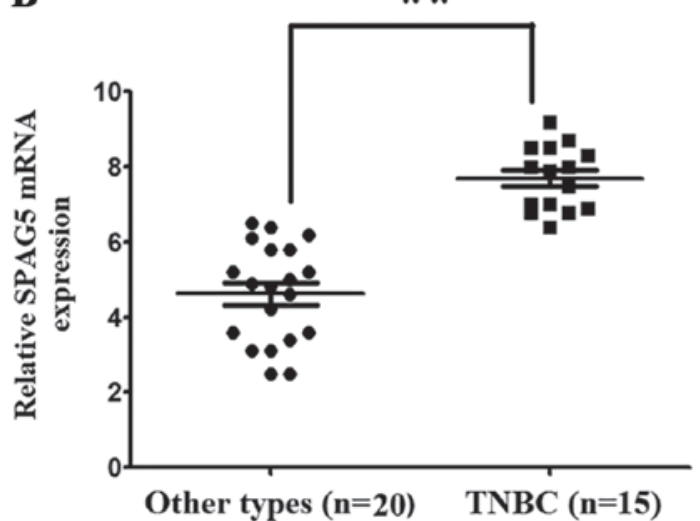

Figure 1. SPAG5 mRNA expression in 35 pairs of BC tissues and matched adjacent nontumor tissues. SPAG5 mRNA expression was detected using reverse transcription-quantitative polymerase chain reaction and normalized to $\beta$-actin. The expression level of SPAG5 mRNA in BC tissues, normal breast tissues, TNBC tissues and non-TNBC tissues was $4.41 \pm 0.53,1.73 \pm 0.28,7.83 \pm 0.13$ and $4.37 \pm 0.19$, respectively. (A) SPAG5 mRNA level was significantly higher in BC tissues compared with matched adjacent nontumor tissues. (B) SPAG5 mRNA level was significantly higher in TNBC tissues compared with other molecular subtypes of BC. Data are presented as mean \pm standard deviation. ${ }^{* *} \mathrm{P}<0.001$. SPAG5, sperm-associated antigen 5; BC, breast cancer; TNBC, triple-negative breast cancer; N, matched adjacent nontumor tissues; T, BC tissues.

A

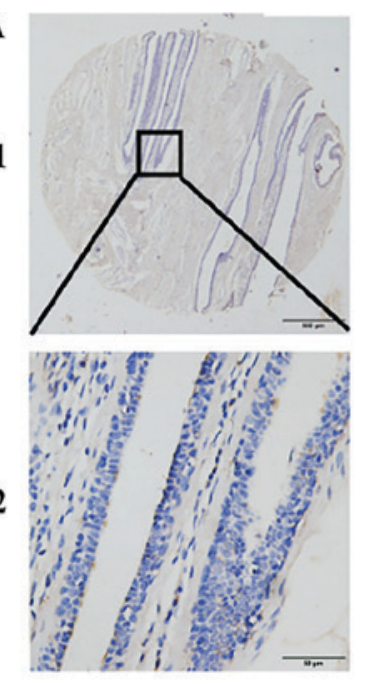

B

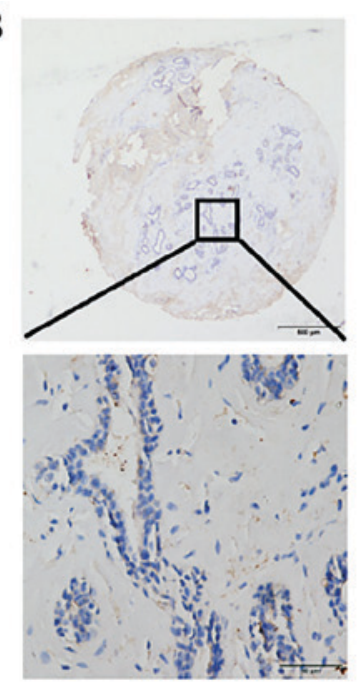

C
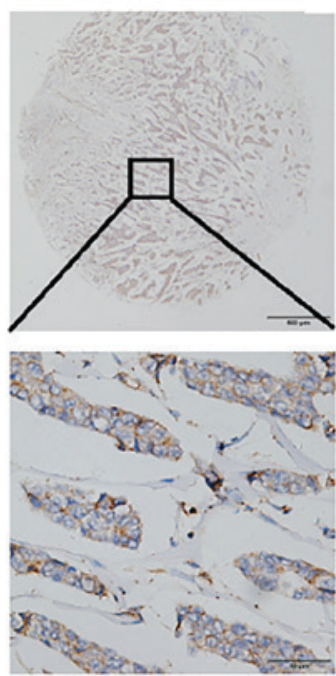

D
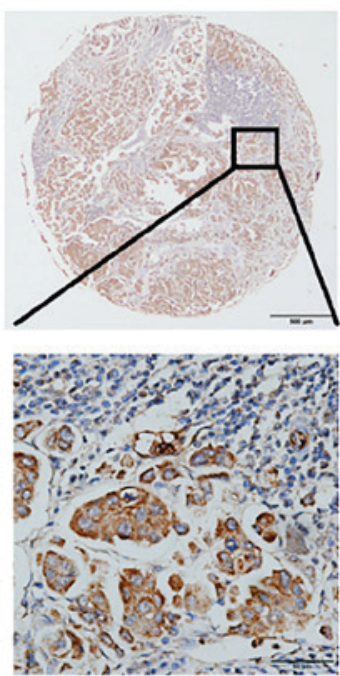

Figure 2. Representative patterns of SPAG5 protein expression in BC tissues on tissue microarray sections. (A) Low expression of SPAG5 in matched adjacent nontumor tissue (IHC score=60). (B) Low expression of SPAG5 in benign tumor tissue (IHC score=50). (C) Weakly positive expression of SPAG5 in BC tissue (IHC score $=150)$. (D) High expression of SPAG5 in BC tissue (IHC score=300). Row 1, SPAG5 staining with magnification, x4, (scale bar, $500 \mu \mathrm{m}$ ); row 2 , SPAG5 staining with magnification, $\mathrm{x} 40$ (scale bar, $50 \mu \mathrm{m}$ ). SPAG5, sperm-associated antigen 5; BC, breast cancer; IHC, immunohistochemistry.

SPAG5 protein is highly expressed in BC tissues. SPAG5 protein expression was demonstrated to be localized to the cytoplasm using IHC (Fig. 2). Furthermore, IHC revealed that SPAG5 protein was highly expressed in BC tissues. Using X-tile software to analyze TMA data, SPAG5 expression was classified as high or low according to OS 
Table II. Association of SPAG5 protein expression levels with clinicopathological characteristics in patients with breast cancer.

\begin{tabular}{|c|c|c|c|c|c|}
\hline \multirow[b]{2}{*}{ Characteristic } & \multirow[b]{2}{*}{$\mathrm{n}$} & \multicolumn{2}{|c|}{ SPAG5 expression, n (\%) } & \multirow[b]{2}{*}{$\chi^{2}$} & \multirow[b]{2}{*}{ P-value } \\
\hline & & Low or none & High & & \\
\hline Total & 159 & & & & \\
\hline Age, years & & & & 1.078 & 0.299 \\
\hline$\leq 60$ & 81 & $62(76.54)$ & $19(23.46)$ & & \\
\hline$>60$ & 78 & $54(69.23)$ & $24(30.77)$ & & \\
\hline Histological grade & & & & 9.965 & 0.007 \\
\hline I & 57 & $33(57.89)$ & $24(42.11)$ & & \\
\hline II & 63 & $51(80.95)$ & $12(19.05)$ & & \\
\hline III & 39 & $32(82.05)$ & $7(17.95)$ & & \\
\hline ER expression & & & & 10.940 & $<0.001$ \\
\hline Positive & 110 & $89(80.91)$ & $21(19.09)$ & & \\
\hline Negative & 49 & $27(55.10)$ & $22(44.90)$ & & \\
\hline PR expression & & & & 3.614 & 0.057 \\
\hline Positive & 97 & $76(78.35)$ & $21(21.65)$ & & \\
\hline Negative & 62 & $40(64.52)$ & $22(35.48)$ & & \\
\hline HER2 expression & & & & 2.856 & 0.091 \\
\hline Positive & 57 & $37(64.91)$ & $20(35.09)$ & & \\
\hline Negative & 102 & $79(77.45)$ & $23(22.55)$ & & \\
\hline Ki-67 expression & & & & 21.799 & $<0.001$ \\
\hline Positive & 63 & $58(92.06)$ & $5(7.94)$ & & \\
\hline Negative & 96 & $58(60.42)$ & $38(39.58)$ & & \\
\hline Tumor size & & & & 15.913 & $<0.001$ \\
\hline $\mathrm{T} 1$ & 75 & $45(60.00)$ & $30(40.00)$ & & \\
\hline $\mathrm{T} 2$ & 54 & $43(79.63)$ & $11(20.37)$ & & \\
\hline T3 and 4 & 30 & $28(93.33)$ & $2(6.67)$ & & \\
\hline Lymph node metastasis & & & & 18.519 & $<0.001$ \\
\hline No & 67 & $37(55.22)$ & $30(44.78)$ & & \\
\hline N1-3 & 92 & 79 (85.87) & $13(14.13)$ & & \\
\hline TNM stage & & & & 11.511 & 0.003 \\
\hline I & 51 & $30(56.82)$ & $21(41.18)$ & & \\
\hline II & 69 & $51(73.91)$ & $18(26.09)$ & & \\
\hline III & 39 & 35 (89.74) & $4(10.26)$ & & \\
\hline TNBC & & & & 10.429 & 0.015 \\
\hline Positive & 140 & $87(62.14)$ & $53(37.86)$ & & \\
\hline Negative & 19 & $15(78.96)$ & $4(21.05)$ & & \\
\hline
\end{tabular}

SPAG5, sperm-associated antigen 5; ER, estrogen receptor; PR, progesterone receptor; HER2, human epidermal growth factor receptor 2; TNM, tumor-node-metastasis; TNBC, triple-negative breast cancer.

for patients with $\mathrm{BC}$. The cutoff value was selected as 130 ; a score of 0-130 was considered low or no expression and a score of 131-300 was considered high expression. High SPAG5 expression was detected more frequently in BC tissues $(116 / 159,72.96 \%)$ compared with benign tumor tissues $(2 / 61,3.28 \%)$ or matched adjacent nontumor tissues (0/159, 0.00\%; Table I).

High SPAG5 expression is associated with clinicopathological characteristics in $B C$. The association between SPAG5 protein expression and clinicopathologic characteristics in $\mathrm{BC}$ tissues was investigated. Results indicated that high expression of SPAG5 in BC was associated with histological grade $\left(\chi^{2}=9.965, \mathrm{P}=0.007\right)$, ER expression $\left(\chi^{2}=10.940, \mathrm{P}<0.001\right)$, Ki-67 expression $\left(\chi^{2}=21.799, \mathrm{P}<0.001\right)$, tumor size $\left(\chi^{2}=15.913\right.$, $\mathrm{P}=0.001)$, lymph node status $\left(\chi^{2}=18.519, \mathrm{P}<0.001\right)$, TNM stage $\left(\chi^{2}=11.511, \mathrm{P}=0.003\right)$ and TNBC subtype $\left(\chi^{2}=10.429\right.$ $\mathrm{P}=0.015)$. However, no significant association was identified between SPAG5 expression and age, PR expression or HER2 expression (Table II). 
Table III. Univariate and multivariate analysis of prognostic markers for overall survival in breast cancer.

\begin{tabular}{|c|c|c|c|c|c|c|}
\hline \multirow[b]{2}{*}{ Characteristic } & \multicolumn{3}{|c|}{ Univariate analysis } & \multicolumn{3}{|c|}{ Multivariate analysis } \\
\hline & HR & P-value & $95 \% \mathrm{CI}$ & HR & $\mathrm{P}$-value & $95 \% \mathrm{CI}$ \\
\hline $\begin{array}{l}\text { SPAG5 } \\
\text { High vs. low or none }\end{array}$ & 1.956 & $<0.001$ & $1.041-2.009$ & 1.523 & 0.043 & $0.323-1.934$ \\
\hline $\begin{array}{l}\text { Age, years } \\
\leq 60 \text { vs. }>60\end{array}$ & 1.014 & 0.778 & $0.652-1.627$ & & & \\
\hline $\begin{array}{l}\text { Histological grade } \\
\text { I vs. II vs. III }\end{array}$ & 1.018 & 0.819 & $0.602-1.713$ & & & \\
\hline $\begin{array}{l}\text { ER } \\
\text { Positive vs. negative }\end{array}$ & 1.012 & 0.969 & $0.621-1.589$ & & & \\
\hline $\begin{array}{l}\text { PR } \\
\text { Positive vs. negative }\end{array}$ & 0.892 & 0.391 & $0.521-1.052$ & & & \\
\hline $\begin{array}{l}\text { HER } 2 \\
\text { Positive vs. negative }\end{array}$ & 0.832 & 0.437 & $0.519-1.192$ & & & \\
\hline $\begin{array}{l}\text { Ki-67 } \\
\text { Positive vs. negative }\end{array}$ & 0.732 & 0.398 & $0.492-1.382$ & & & \\
\hline $\begin{array}{l}\text { Tumor size, } \mathrm{cm} \\
\leq 2 \text { vs. }>2\end{array}$ & 0.819 & 0.308 & $0.528-1.103$ & & & \\
\hline $\begin{array}{l}\text { Lymph node status } \\
\text { N0 vs. N1-3 }\end{array}$ & 10.92 & 0.000 & 4.109-18.723 & 3.829 & $<0.001$ & $1.292-7.303$ \\
\hline $\begin{array}{l}\text { TNM stage } \\
\text { I vs. II vs. III }\end{array}$ & 2.192 & $<0.001$ & $1.528-2.428$ & 1.368 & 0.061 & $0.928-1.927$ \\
\hline $\begin{array}{l}\text { TNBC } \\
\text { Positive vs. negative }\end{array}$ & 3.892 & $<0.001$ & $2.829-5.628$ & 3.923 & $<0.001$ & $1.802-6.193$ \\
\hline
\end{tabular}

HR, hazard ratio; CI, confidence interval; SPAG5, sperm-associated antigen 5; ER, estrogen receptor; PR, progesterone receptor; HER2, human epidermal growth factor receptor 2; TNM, tumor-node-metastasis; TNBC, triple-negative breast cancer.

A

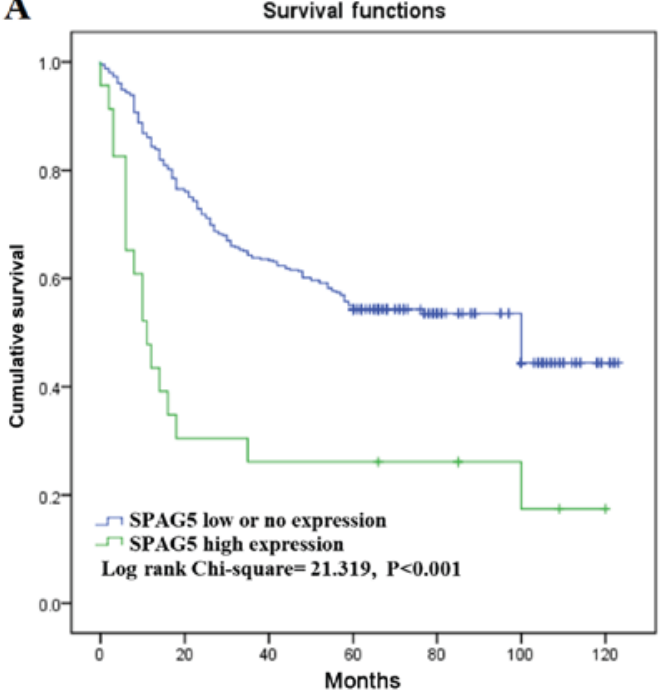

B

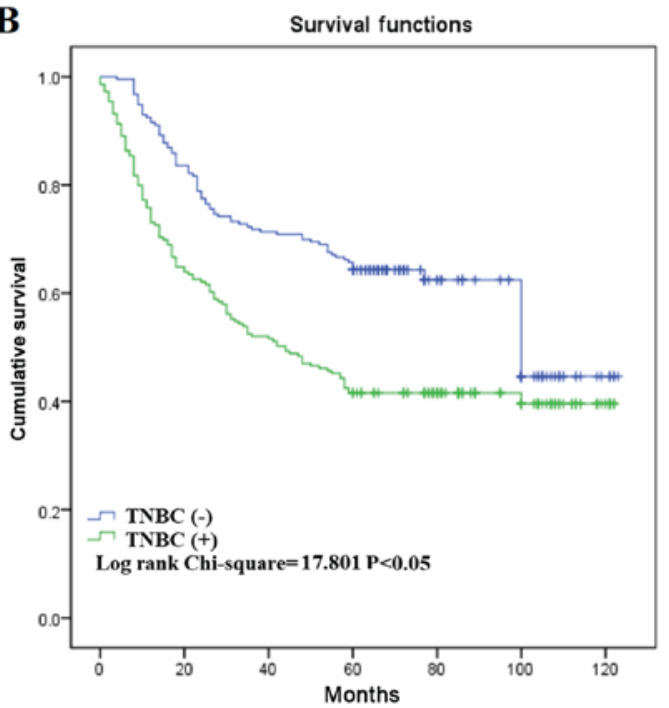

Figure 3. Survival curves for breast cancer using Kaplan-Meier analysis and log-rank test. (A) Overall survival curves for patients with low and high SPAG5 expression. (B) Overall survival curves for patients with and without TNBC. SPAG5, sperm-associated antigen 5; TNBC, triple-negative breast cancer.

High expression of SPAG5 protein is associated with a poor prognosis in $B C$. Lastly, the current study investigated the association between SPAG5 expression and prognostic factors in $\mathrm{BC}$ through univariate and multivariate analyses. 
High SPAG5 expression level was associated with poor OS in univariate analysis $[\mathrm{HR}=1.956 ; 95 \%$ confidence interval $(\mathrm{CI})=1.040-2.009 ; \mathrm{P}<0.001)$. OS was also identified to be associated with other prognostic markers, including TNM stage $(\mathrm{HR}=10.92 ; 95 \% \mathrm{CI}=4.109-18.723 ; \mathrm{P}<0.001)$, lymph node status $(\mathrm{HR}=2.192 ; 95 \% \mathrm{CI}=1.528-2.428 ; \mathrm{P}<0.001)$ and $\mathrm{TNBC}$ $(\mathrm{HR}=3.892 ; 95 \% \mathrm{CI}=2.829-5.628 ; \mathrm{P}<0.001)$. Multivariate analysis revealed that only high SPAG5 expression, molecular classification and TNM stage were associated with poor OS (Table III). Similar results were identified using Kaplan-Meier survival analysis; this indicated that SPAG5 high expression and the TNBC-positive subtype were significantly associated with poor OS (Fig. 3).

\section{Discussion}

$\mathrm{BC}$ is regarded as a heterogeneous disease that can be classified into several molecular subtypes with prognostic significance (15). According to ER, PR, HER2 and Ki-67 expression status, BC can be categorized into four molecular subtypes, which can be used to predict outcome and contribute to the management of BC (7). TNBC typically predicts a poor prognosis and is characterized by no ER and PR expression, and no overexpression of HER2 (17). The majority of patients with TNBC have an aggressive tumor phenotype and exhibit a partial response to chemotherapy (17). Due to the aforementioned reasons, new targets are required for TNBC therapy.

SPAG5 serves an important role in cell meiosis and spermatid morphogenesis $(10,18)$. Certain studies have indicated that knockdown of SPAG5 expression in cervical cancer cells can inhibit cell proliferation and induce cell apoptosis, thereby decreasing the ability of cancer cells to invade $(19,20)$. According to the aforementioned studies, SPAG5 is currently considered to serve a role in promoting tumor cell growth. Cornen et al (21) reported that SPAG5 expression may be associated with the molecular classification of $\mathrm{BC}$ and is a potential oncogene in luminal BC.

Using RT-qPCR, the current study identified SPAG5 mRNA overexpression in fresh BC tumor tissues compared with matched adjacent nontumor tissues, particularly in TNBC tissues. A monoclonal antibody that recognizes an epitope in the SPAG5 protein was then used to demonstrate that SPAG5 was highly expressed in BC tissues and was associated with histological grade, ER expression, Ki-67 expression, lymph node status, TNM stage and TNBC subtype. Previously, studies have demonstrated that SPAG5 is highly expressed in BC tissues and is associated with tumor classification, p53 mutation and the amplification of HER2 (6). The current study also revealed that overexpression of SPAG5 predicted poor OS in patients with $\mathrm{BC}$. This is similar to findings made by Abdel-Fatah et al (15), who reported that higher expression of SPAG5 was associated with a poor prognosis in patients with BC. Abdel-Fatah et al (15) reported that the role of SPAG5 could replace $\mathrm{Ki} 67$ as another proliferation factor. The current study also identified that SPAG5 protein expression was associated with Ki67 expression. In contrast to the study by Abdel-Fatah et al (15), the current study analyzed the association between SPAG5 protein expression and TNBC type, which may provide a new standard for the diagnosis of TNBC type in the future.
In conclusion, the current study indicated that high expression of SPAG5 may be associated with a poor prognosis in patients with $\mathrm{BC}$, which may lead to the development of useful and effective targeted drugs for the treatment of $\mathrm{BC}$.

\section{Acknowledgments}

Not applicable.

\section{Funding}

The current study was supported by the Science and Technology Development Fund of Nanjing Medical University (grant no. 2017NJMUZD107).

\section{Availability of data and materials}

The datasets used and/or analyzed during the current study are available from the corresponding author on reasonable request.

\section{Authors' contributions}

XZ and QT designed the study; LJ, YS acquired the data and drafted the article; LJ, XW, LX and XZ analyzed and interpreted the data. All authors read and approved the final manuscript.

\section{Ethics approval and consent to participate}

The study has been approved by the Human Research Ethics Committee of the Affiliated Hospital of Nantong University (Nantong, China). Written informed consent was obtained from all patients involved in the current study.

\section{Patient consent for publication}

Written informed consent was obtained from all patients involved in the current study.

\section{Competing interests}

The authors declare that they have no competing interests.

\section{References}

1. Beiki O, Hall P, Ekbom A and Moradi T: Breast cancer incidence and case fatality among 4.7 million women in relation to social and ethnic background: A population-based cohort study. Breast Cancer Res 14: R5, 2012.

2. Yang YL, Qian XL and Fu L: Comparison of HER2 status of breast cancer between Chinese women in China and Chinese-American women in the US. Breast J 23: 764-765, 2017.

3. Wang J, Li Q, Xu B, Zhang T, Chen S and Luo Y: Efficacy and safety of duloxetine in Chinese breast cancer patients with paclitaxel-induced peripheral neuropathy. Chin J Cancer Res 29: 411-418, 2017.

4. Peng R, Luo C, Guo Q, Cao J, Yang Q, Dong K, Wang S, Wang K and Song C: Association analyses of genetic variants in long non-coding RNA MALAT1 with breast cancer susceptibility and mRNA expression of MALAT1 in Chinese Han population. Gene 642: 241-248, 2018

5. Abrahams HJ, Gielissen MF, Schmits IC, Verhagen CA, Rovers MM and Knoop H: Risk factors, prevalence, and course of severe fatigue after breast cancer treatment: A meta-analysis involving 12327 breast cancer survivors. Ann Oncol 27: 965-974, 2016. 
6. Rossing M, Østrup O, Majewski WW, Kinalis S, Jensen MB Knoop A, Kroman N, Talman ML, Hansen TVO, Ejlertsen B and Nielsen FC: Molecular subtyping of breast cancer improves identification of both high and low risk patients. Acta Oncol 57: 58-66, 2018.

7. Perou CM, Sørlie T, Eisen MB, van de Rijn M, Jeffrey SS, Rees CA, Pollack JR, Ross DT, Johnsen H, Akslen LA, et al: Molecular portraits of human breast tumours. Nature 406 : 747-752, 2000

8. Stathopoulos GP, Malamos NA, Markopoulos C, Polychronis A, Armakolas A, Rigatos S, Yannopoulou A, Kaparelou M and Antoniou P: The role of $\mathrm{Ki}-67$ in the proliferation and prognosis of breast cancer molecular classification subtypes. Anticancer Drugs 25: 950-957, 2014

9. Xue J, Tarnasky HA, Rancourt DE and van Der Hoorn FA: Targeted disruption of the testicular SPAG5/deepest protein does not affect spermatogenesis or fertility. Mol Cell Biol 22 1993-1997, 2002.

10. Shao X, Xue J and van der Hoorn FA: Testicular protein Spag5 has similarity to mitotic spindle protein Deepest and binds oute dense fiber protein Odf1. Mol Reprod Dev 59: 410-416, 2001.

11. Fitzgerald CJ, Oko RJ and van der Hoorn FA: Rat Spag5 associates in somatic cells with endoplasmic reticulum and microtubules but in spermatozoa with outer dense fibers. Mol Reprod Dev 73: 92-100, 2006.

12. Zhong W, Zhou Y, Li J, Mysore R, Luo W, Li S, Chang MS, Olkkonen VM and Yan D: OSBP-related protein 8 (ORP8) interacts with Homo sapiens sperm associated antigen 5 (SPAG5) and mediates oxysterol interference of HepG2 cell cycle. Exp Cell Res 322: 227-235, 2014.

13. Kersten FF, van Wijk E, Hetterschijt L, Bau $\beta$ K, Peters TA, Aslanyan MG, van der Zwaag B, Wolfrum U, Keunen JE, Roepman $\mathrm{R}$ and Kremer $\mathrm{H}$ : The mitotic spindle protein SPAG5/Astrin connects to the Usher protein network postmitotically. Cilia 1: 2, 2012.
14. Yuan LJ, Li JD, Zhang L, Wang JH, Wan T, Zhou Y, Tu H, Yun JP, Luo RZ, Jia WH and Zheng M: SPAG5 upregulation predicts poor prognosis in cervical cancer patients and alters sensitivity to taxol treatment via the mTOR signaling pathway. Cell Death Dis 6: e1784, 2015.

15. Abdel-Fatah TMA, Agarwal D, Liu DX, Russell R, Rueda OM, Liu K, Xu B, Moseley PM, Green AR, Pockley AG, et al: SPAG5 as a prognostic biomarker and chemotherapy sensitivity predictor in breast cancer: A retrospective, integrated genomic, transcriptomic, and protein analysis. Lancet Oncol 17: 1004-1018, 2016.

16. Livak KJ and Schmittgen TD: Analysis of relative gene expression data using real-time quantitative PCR and the 2(-Delta Delta C(T)) method. Methods 25: 402-408, 2001.

17. Stovgaard ES, Nielsen D, Hogdall E and Balslev E: Triple negative breast cancer-prognostic role of immune-related factors: A systematic review. Acta Oncol 57: 74-82, 2018.

18. Kierszenbaum AL: Spermatid manchette: Plugging proteins to zero into the sperm tail. Mol Reprod Dev 59: 347-349, 2001.

19. Podo F, Buydens LM, Degani H, Hilhorst R, Klipp E, Gribbestad IS, Van Huffel S, van Laarhoven HW, Luts J, Monleon D, et al: Triple-negative breast cancer: Present challenges and new perspectives. Mol Oncol 4: 209-229, 2010.

20. Zhang H, Li S, Yang X, Qiao B, Zhang Z and Xu Y: miR-539 inhibits prostate cancer progression by directly targeting SPAG5. J Exp Clin Cancer Res 35: 60, 2016.

21. Cornen S, Guille A, Adélaïde J, Addou-Klouche L, Finetti P, Saade MR, Manai M, Carbuccia N, Bekhouche I, Letessier A, et al: Candidate luminal B breast cancer genes identified by genome, gene expression and DNA methylation profiling. PLoS One 9: e81843, 2014.

This work is licensed under a Creative Commons Attribution-NonCommercial-NoDerivatives 4.0 International (CC BY-NC-ND 4.0) License. 